\title{
Matriz óssea homóloga desmineralizada associada à medula óssea autógena fresca na artrodese vertebral dorsolateral lombar em coelhos
}

\author{
[Homologous demineralized bone matrix associated to autologous bone marrow \\ in a rabbit dorsolateral lumbar vertebral fusion] \\ D. Rizzo, R.J. Del Carlo ${ }^{*}$, A.S.A. Silva, M.I.V. Viloria, P.S.A. Silva, F.F. Pagani \\ Departamento de Veterinária - Universidade Federal de Viçosa \\ Campus Universitário \\ Av. PH Rolfs, s/n \\ 36570-000 - Viçosa, MG
}

\begin{abstract}
RESUMO
Foi avaliada a matriz óssea homóloga desmineralizada (MOD), associada à medula óssea autógena fresca (MO), na artrodese vertebral dorsolateral lombar em 24 coelhos (grupo 1), depositada sobre os processos transversos de $\mathrm{L}_{5}-\mathrm{L}_{6}$ previamente descorticados. Em outros nove coelhos (grupo-controle), foi realizada apenas a descorticação dos processos transversos e nas diferentes avaliações, foi observada insignificante reação periosteal local, sem união óssea. No grupo 1, às cinco semanas de pós-operatório, $87,5 \%$ dos animais apresentaram união (artrodese) à palpação, seguido por 75 e $100 \%$ às sete e nove semanas, respectivamente. Os índices de artrodese aos $\mathrm{RX}$ foram de $50 \%, 62 \%$ e $75 \%$, no mesmo período de avaliação. Histologicamente, às cinco semanas havia características de osteointegração da MOD com os processos transversos descorticados, de onde partiram os vasos sangüíneos que penetraram a matriz, e presença de ilhas de cartilagem no centro do enxerto. Nas semanas seguintes, a ossificação endocondral evoluiu e a MOD foi quase totalmente substituída por tecido ósseo trabecular, formando uma ponte de osso maduro entre e sobre os processos transversos adjacentes, propiciando ao segmento operado maior resistência mecânica em comparação aos segmentos adjacentes. A associação da MOD com a MO mostrou-se uma opção exeqüível e de baixo custo na artrodese vertebral dorsolateral lombar em coelhos.
\end{abstract}

Palavras-chave: artrodese vertebral, matriz óssea desmineralizada, medula óssea.

\begin{abstract}
It was evaluated the homologous demineralized bone matrix (HDBM), associated with the fresh autogenous bone marrow (FABM), in the vertebral dorsolateral lumbar union in 24 rabbits (group 1), that was placed on the transverse processes of previously decorticated L5-L6 vertebrae. In other nine rabbits (control group), it was just accomplished the decortications of the transverse processes, which showed insignificant local periostial reaction, without bone union after different evaluations. In the group 1, after five weeks of postoperative interval, $87.5 \%$ of the animals presented union (arthrodesis), which was observed by palpation, followed by 75 and $100 \%$ after seven and nine weeks, respectively. The arthrodesis indexes to $X$ rays were of $50 \%, 62 \%$ and $75 \%$, in the same evaluation period. According to histological analysis, after five weeks, there were characteristics of osteointegration of HDBM with the decorticated transverse processes, from where the blood vessels that penetrated the bone matrix originated, and the presence of cartilage tissue in the center of the graft. In the following weeks, the endocondral ossification continued and HDBM was almost totally substituted by trabecular bone tissue,
\end{abstract}

Recebido para publicação em 24 de dezembro de 2003

Recebido para publicação, após modificações, em 29 de março de 2004

Apoio financeiro FAPEMIG e CNPq

*Autor para correspondência (corresponding author)

E-mail: ricarlo@ufv.br 
forming a bridge of ripe bone among and over the adjacent transverse processes, propitiating larger mechanical resistance to the operated segment in comparison to the adjacent segments. The association of HDBM with the FABM showed as a feasible option with low cost in the vertebral dorsolateral lumbar arthrodesis in rabbits.

Keywords: vertebral fusion, demineralized bone matrix, bone marrow

\section{INTRODUÇÃO}

O método padrão para artrodese posterolateral lombar utiliza o autoenxerto da crista ilíaca (Feighan at al., 1995). Os riscos relacionados a esse tipo de procedimento incluem: não-união, que pode variar de 10 a $50 \%$ (Cook et al., 1995) e requer nova cirurgia; quantidade insuficiente de material disponível para coleta e artrodese e possibilidade de ocorrência de parestesia no local de coleta, até três anos após a cirurgia, no ser humano (Martin et al., 1999).

O aloenxerto de matriz óssea desmineralizada (MOD) pode ser utilizado como alternativa, eliminando as complicações relacionadas com o sítio doador (Guizard et al., 1992). O baixo potencial osteogênico, alto índice de reabsorção e a pequena revascularização podem limitar sua eficácia (Damien e Parsons, 1991).

A medula óssea (MO) possui células primordiais indiferenciadas, denominadas células tronco, que possuem o potencial de se diferenciarem em células da linhagem óssea (Barros et al., 2001). Frenkel et al. (1993) demonstraram que a adição da MO pode aumentar a quantidade de osso formado e, conseqüentemente, o sucesso da artrodese.

A MOD apresenta a habilidade de aderir e fornecer moléculas bioativas (BMP) que, associadas à presença de células osteoprogenitoras no local de enxertia, assim como aos fatores bioativos provenientes da medula óssea autógena fresca, ampliam o potencial osteoindutor (Maddox et al., 2000).

O objetivo deste estudo foi avaliar a capacidade da matriz óssea homóloga desmineralizada, associada à medula óssea autógena fresca, de promover a artrodese vertebral dorsolateral lombar em coelhos.

\section{MATERIAL E MÉTODO}

Foram utilizados 33 coelhos machos e fêmeas, clinicamente sadios, com oito semanas de idade, da raça Nova Zelândia Branca e peso médio de $3 \mathrm{~kg}$. Os animais, mantidos em gaiolas individuais e alimentados com ração comercial e feno, foram distribuídos aleatoriamente em dois grupos. O grupo 1 (G1) foi composto por 24 coelhos que receberam aloenxerto de matriz óssea desmineralizada, bilateralmente, sobre os processos transversos descorticados das vértebras lombares cinco e seis $\left(\mathrm{L}_{5}\right.$ e $\left.\mathrm{L}_{6}\right)$. $\mathrm{O}$ grupo $2(\mathrm{G} 2)$ constituído de nove coelhos, cujos processos transversos de $\mathrm{L}_{5}$ e $\mathrm{L}_{6}$ foram descorticados, bilateralmente, foi utilizado como controle. Oito coelhos do G1 e três do G2 foram escolhidos de forma aleatória e submetidos à eutanásia em cada período de observação: às cinco, sete e nove semanas do pós-operatório.

A MOD foi coletada a partir da diáfise de fêmur de outros coelhos da mesma raça e porte, sacrificados com sobredosagem anestésica (tiopental sódico). Após a remoção de todo tecido mole, com auxílio de bisturi, as diáfises foram desmineralizadas por imersão em ácido hidroclorídrico $0,6 \mathrm{~N}$, por 24 a 48 horas, em temperatura ambiente. $\mathrm{O}$ ácido foi trocado a cada 24 horas e o osso, considerado desmineralizado quando se apresentou flexível e transparente, foi estocado em álcool $70^{\circ} \mathrm{GL}$ à temperatura ambiente. No momento da cirurgia, o osso foi cortado em seu eixo longitudinal e em segmentos de, aproximadamente, $0,5 \mathrm{~cm}$ de largura por $2,0 \mathrm{~cm}$ de comprimento.

Cada coelho recebeu como medicação préanestésica maleato de acepromazina $(0,1 \mathrm{mg} / \mathrm{kg} / \mathrm{IV})$, seguida de anestesia dissociativa com tiletamina-zolazepam (20mg/kg/IV), associada à infiltração de anestésico local, na dose de $0,75 \mathrm{ml}$. Antibioticoterapia foi realizada com ceftiofur sódico $(5 \mathrm{mg} / \mathrm{kg} / \mathrm{IM})$, no período pré-operatório e 24 e 48 horas após o procedimento cirúrgico. 
Os animais foram posicionados em decúbito ventral, com os membros pélvicos estendidos cranialmente. $\mathrm{O}$ procedimento iniciou-se com uma incisão de pele na linha média dorsal lombar, de aproximadamente $5 \mathrm{~cm}$ de extensão, tendo como referência os processos transversos de $\mathrm{L}_{5}$ e $\mathrm{L}_{6}$. Bilateralmente, foi realizada uma incisão na fáscia paramediana após a infiltração de $0,5 \mathrm{ml}$ de lidocaína. Os músculos multifidus e longissimus foram identificados e o plano entre eles foi divulsionado, permitindo a exposição dos processos transversos de $\mathrm{L}_{5} \mathrm{e}_{6}$ e da membrana intertransversa. Com o auxílio de um osteótomo, a face dorsal desses processos, de ambos os lados, foi descorticada até visibilizar a região óssea medular, permitindo a deposição da MOD.

A MO foi obtida durante o período transoperatório, pela aspiração com agulha para punção medular (16 G), acoplada a seringa estéril de $20 \mathrm{ml}$, heparinizada (após aspiração e devolução do conteúdo ao frasco de heparina $5000 \mathrm{UI} / \mathrm{ml}$ ), inserida na crista ilíaca posterior até a cavidade medular, segundo técnica descrita por Barros et al. (2001). Imediatamente após a coleta, $2 \mathrm{ml}$ de medula integral foram depositados no local de enxertia, bilateralmente, sobre toda a extensão da MOD.

A fáscia paramediana e o tecido subcutâneo foram suturados com categute cromado 4-0, em padrão de sutura Reverdin, e a pele aproximada com fio de náilon 4-0, em padrão contínuo simples. A analgesia pós-operatória foi obtida com sulfato de morfina $(0,4 \mathrm{mg} / \mathrm{kg}, \mathrm{VO}$, qid), durante os três primeiros dias após o procedimento cirúrgico.

As avaliações radiográficas foram feitas na incidência dorso-ventral, em todos os animais, imediatamente após o procedimento cirúrgico e à eutanásia. As análises basearam-se na presença de massa óssea uni ou bilateralmente, sendo caracterizada artrodese na presença de massa óssea intertransversa bilateral, sem radioluscência.

Após a eutanásia, a coluna vertebral lombar foi removida e os segmentos entre $\mathrm{L}_{5}$ e $\mathrm{L}_{6}$ foram palpados, assim como os segmentos adjacentes, proximal e distal, permitindo classificá-los quando sólidos e firmes à movimentação, como artrodese vertebral.
A avaliação histológica foi realizada em 12 e nove animais do G1 e G2, quatro e três a cada momento da eutanásia, respectivamente. Os cortes histológicos foram corados com hematoxilina-eosina e tricrômico de Masson. A massa de união sobre os espaços interlaminares foi analisada com base no tipo de tecido de reparação predominante.

A avaliação da resistência à tração foi realizada em 12 animais do G1, quatro a cada semana de eutanásia, escolhidos aleatoriamente. Imediatamente antes do teste, todo o tecido muscular remanescente, os discos intervertebrais e os processos articulares foram removidos com o auxílio de um bisturi, mantendo a massa de união e a membrana intertransversa conectadas às duas vértebras unidas. Posteriormente, os corpos vertebrais das vértebras $\mathrm{L}_{5} \mathrm{e}_{6} \mathrm{~L}_{6}$ foram perfurados perpendicularmente com pinos de aço de $3,2 \mathrm{~mm}$ de diâmetro e $12 \mathrm{~cm}$ de comprimento, posicionados paralelamente entre si. Um sistema composto de correntes foi acoplado aos pinos e ao aparelho de tração. A carga de tração foi aplicada seqüencialmente ao deslocamento e seus valores registrados em Newtons (N). Os dados do deslocamento foram registrados em milímetros.

O teste foi realizado no laboratório de papel e celulose (LPC) da Universidade Federal de Viçosa (UFV), utilizando tensiômetro ${ }^{1}$. As propriedades avaliadas foram: força máxima ao ponto de ruptura (força necessária para romper totalmente o corpo de prova, expressa em $\mathrm{N}$ ou um de seus múltiplos); força ao limite de elasticidade (força absorvida pelo corpo de prova no seu limite máximo de elasticidade, ou seja, o corpo manteve a capacidade de retornar à sua estrutura original, sem sofrer deformação, expressa em $\mathrm{N}$ ) e rigidez (habilidade do corpo de prova resistir às deformações em função das tensões aplicadas, expressa em N/cm).

Também foram calculados os índices de união: força máxima do grupo tratado pela força máxima do controle; força limite de elasticidade do tratado pela força limite de elasticidade do controle e razão da rigidez do tratado pela rigidez do controle.

\footnotetext{
${ }^{1}$ Instron, modelo 4204, São Paulo, Brasil.
} 
Os dados radiográficos para a presença de união nos dois grupos, assim como a avaliação por palpação e os dados histológicos foram analisados de forma descritiva, comparando-os e avaliando evidências de artrodese. Os resultados do teste de resistência à tração foram avaliados pelo teste $\mathrm{t}$ de Student, para comparação entre duas médias de amostras aleatórias independentes $(\mathrm{P}<0,05)$.

\section{RESULTADOS}

Todos os animais toleraram bem o procedimento cirúrgico, deambulando imediatamente após a recuperação anestésica e locomovendo-se normalmente no dia seguinte à cirurgia. Todas as feridas cirúrgicas cicatrizaram em primeira intenção. Em dois animais do G1, submetidos à eutanásia às sete semanas, foi observado abscesso unilateral, próximo à região da enxertia. Nesses casos, a MOD encontrava-se intacta e não aderida aos processos transversos.

Durante o teste de palpação, em todos os momentos de eutanásia, os segmentos vertebrais adjacentes a $\mathrm{L}_{5}$ e $\mathrm{L}_{6}$, bem como os segmentos descorticados dos nove animais do grupocontrole, apresentaram mobilidade, não revelando sinais de união. Os segmentos que receberam a MOD associada à $\mathrm{MO}$ às cinco semanas apresentaram índice de união de 87,5\%, às sete semanas de $75 \%$ e às nove, de $100 \%$ (Tab. 1).

Tabela 1. Resultado da palpação (PM) e da avaliação radiográfica (AR) do segmento $\mathrm{L}_{5}-\mathrm{L}_{6}$, em função do tempo pós-operatório, nas vértebras lombares submetidas a artrodese com matriz óssea desmineralizada e medula óssea

\begin{tabular}{|c|c|c|c|c|c|c|}
\hline \multirow{2}{*}{ Característica } & \multicolumn{2}{|c|}{5 semanas } & \multicolumn{2}{|c|}{7 semanas } & \multicolumn{2}{|c|}{9 semanas } \\
\hline & PM & $\mathrm{AR}$ & PM & $\mathrm{AR}$ & PM & $\mathrm{AR}$ \\
\hline Com artrodese & $7(87,5)$ & $4(50,0)$ & $6(75,0)$ & $5(62,5)$ & $8(100,0)$ & $6(75,0)$ \\
\hline Não união & $1(12,5)$ & $4(50,0)$ & $2(25,0)$ & $3(37,5)$ & 0 & $2(25,0)$ \\
\hline
\end{tabular}

$\mathrm{N}=8$. Valores entre parêntesis representam a \%

À análise radiográfica do $\mathrm{G} 1$ às cinco semanas, quatro animais $\quad(50 \%)$ apresentaram radiopacidade na área de enxertia, unindo dois processos transversos bilateralmente, considerados artrodese. Às sete semanas, essa condição ocorreu em cinco coelhos $(62 \%)$ e às nove, em seis $(75 \%)$. Estes resultados são apresentados na Tab. 1 e Fig. 1.

No grupo 2, nos três momentos avaliados, houve apenas mínima reação periosteal sobre os processos transversos, condição observada histológica e radiograficamente (Fig. 1).

Histologicamente, às cinco semanas, no G1 foram observadas características de osteointegração da MOD com os processos transversos, sendo a matriz penetrada por vasos sangüíneos e ocorrendo formação de tecido condróide na interface, seguida por crescimento ósseo endocondral. Houve também formação de tecido condróide no centro do enxerto, coincidente com o local de deposição da medula óssea autógena fresca, caracterizando centro de ossificação (Fig. 2A).
Às sete semanas a matriz continuou a ser reabsorvida e substituída por tecido condróide em toda sua extensão, principalmente a partir dos processos transversos. Foi observada presença de ilhas cartilaginosas no centro do enxerto, ocorrendo também ossificação endocondral e formação de osso imaturo (Fig. 2B).

Às nove semanas, o processo de ossificação endocondral continuou a evoluir e a MOD foi substituída em quase sua totalidade por tecido ósseo, com trabéculas formando ponte de osso maduro entre dois processos transversos adjacentes (Fig. 2C).

No teste de resistência à tração houve diferença significativa entre as vértebras que receberam a MOD associada à medula óssea e as vértebras adjacentes, utilizadas como controle, quanto à força ao ponto de ruptura e força ao limite de elasticidade. Contudo, não houve diferença significativa entre as semanas analisadas. Os resultados dos testes biomecânicos são apresentados nas Tab. 1 e 2 . 

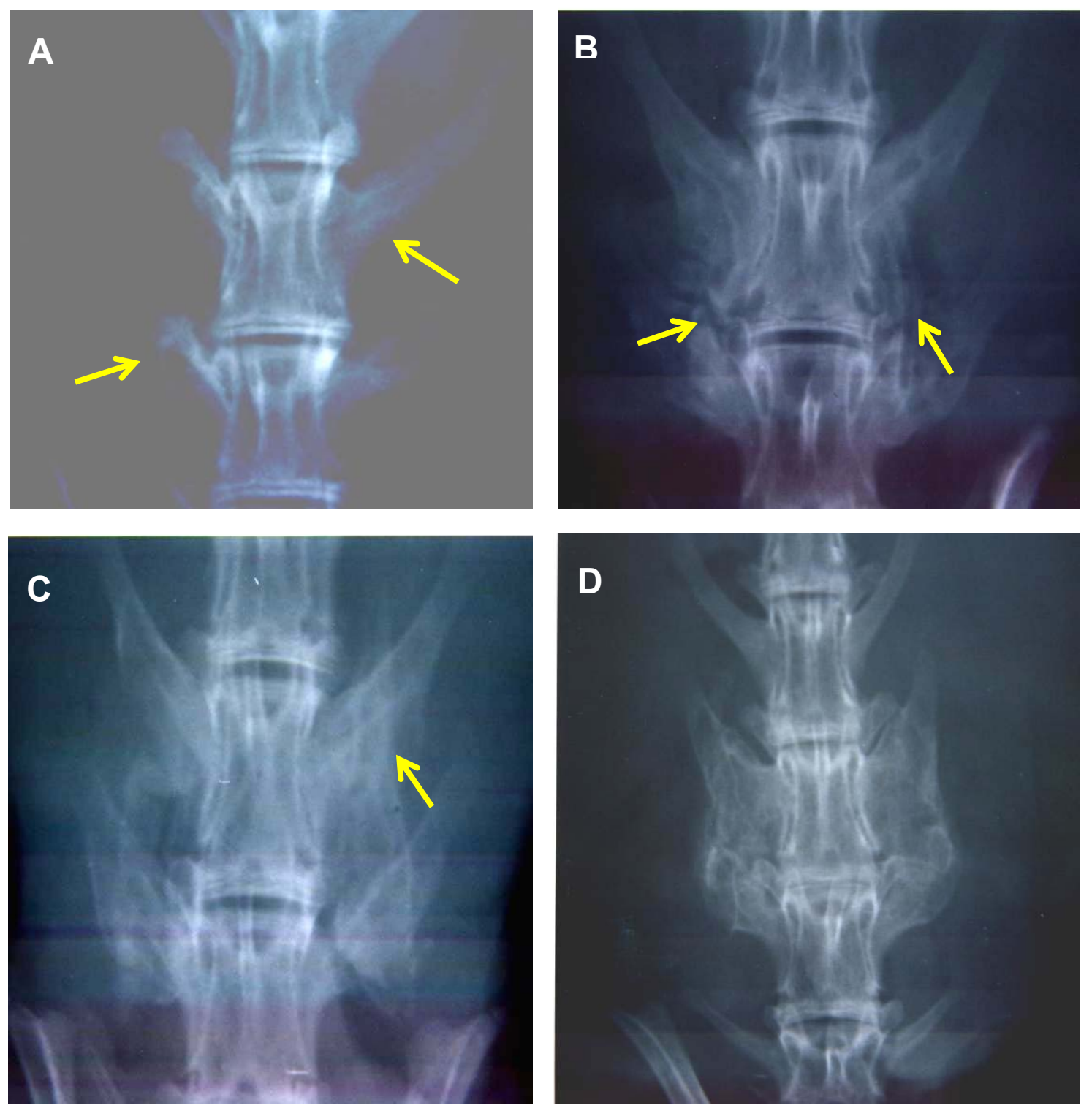

Figura 1. Aspecto radiográfico após a cirurgia. (A) às nove semanas após a descorticação dos processos transversos sem a adição de enxerto: reação periosteal (setas). (B) às cinco semanas após enxertia com MOD associada à MO: presença de áreas radiolucentes (setas), não formando ponte óssea entre dois processos transversos adjacentes bilateralmente. (C) às sete semanas após cirurgia: artrodese unilateral (seta). (D) às nove semanas após a cirurgia: artrodese bilateral. 

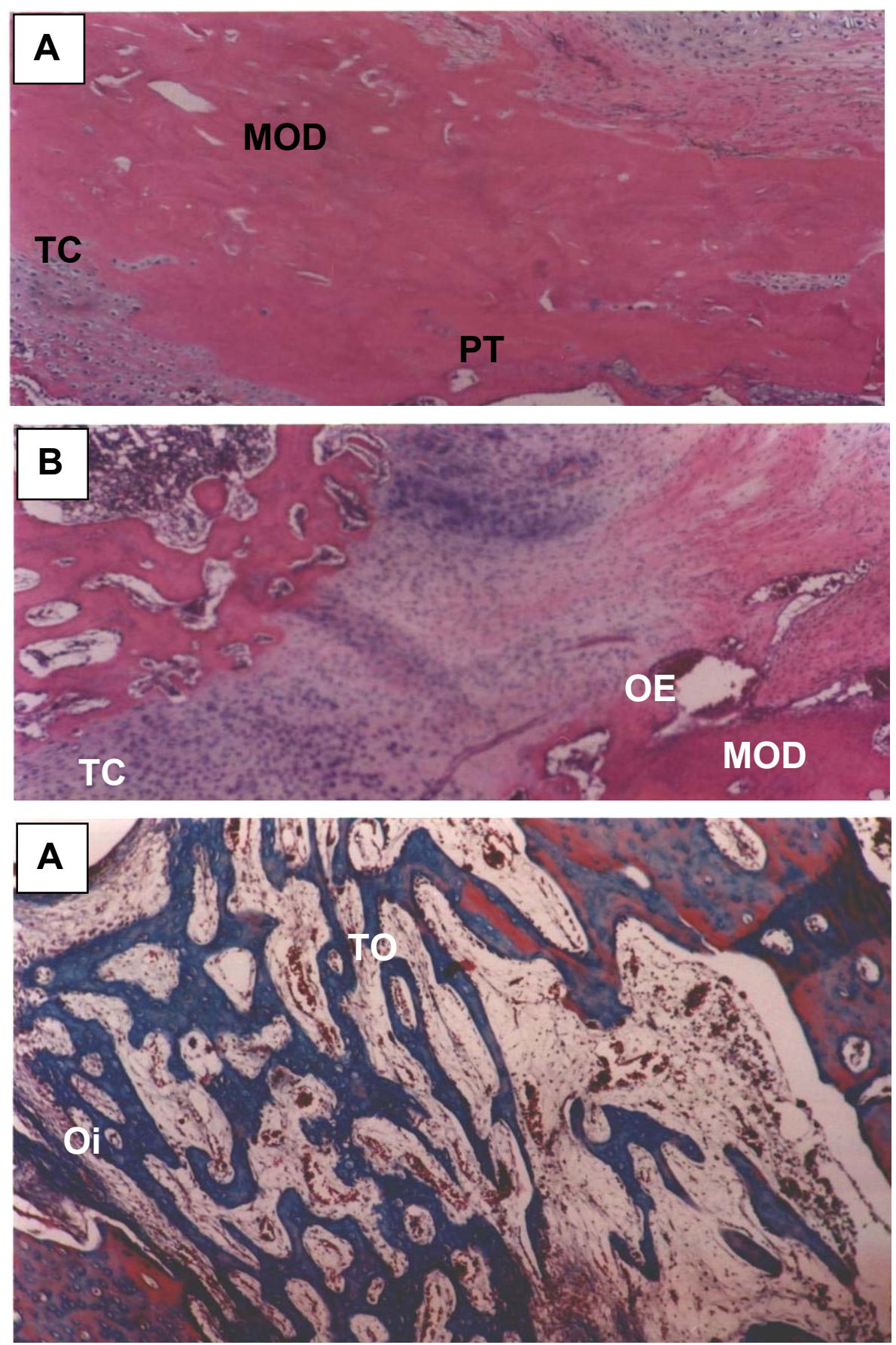

Figura 2. A. Fotomicrografia da região de enxertia, às cinco semanas após a cirurgia: integração do enxerto (MOD) ao processo transverso (PT), MOD sendo reabsorvida e substituída por tecido condróide (TC). Formação de tecido condróide (seta) no centro da MOD. H \& E. 63 X. B. Fotomicrografia da região de enxertia às sete semanas após a cirurgia: ossificação endocondral $(\mathrm{OE})$ substituindo a matriz óssea desmineralizada (MOD). Tecido condróide (TC) e Processo transverso (PT). H \& E. 63 X. C. Fotomicrografia da região de enxertia às nove semanas após a cirurgia: região central do enxerto substituída predominantemente por tecido ósseo trabecular (TO) e tecido ósseo imaturo (Oi). Tricrômico de Masson. 63 X. 
Matriz óssea homóloga desmineralizada...

Tabela 2. Médias dos resultados dos testes de resistência a tração realizados nas vértebras $\mathrm{L}_{5}-\mathrm{L}_{6}$, tratadas (VT), em relação às vértebras $\mathrm{L}_{3}-\mathrm{L}_{4}$, não tratadas (NT), em função do tempo

\begin{tabular}{lccccccccc}
\hline & \multicolumn{9}{c}{ Teste de tração } \\
\cline { 2 - 9 } Semanas & \multicolumn{1}{c}{ Força máxima } & Índice & \multicolumn{2}{c}{ Força limite } & Índice & \multicolumn{2}{c}{ Rigidez } & Índice \\
\cline { 2 - 9 } & $\mathrm{VT}$ & $\mathrm{NT}$ & $\mathrm{T} / \mathrm{N}$ & $\mathrm{VT}$ & $\mathrm{NT}$ & $\mathrm{T} / \mathrm{N}$ & $\mathrm{VT}$ & $\mathrm{NT}$ & $\mathrm{T} / \mathrm{N}$ \\
\hline Cinco & $326,7 \mathrm{aA}$ & $149,1 \mathrm{aB}$ & 2,1 & $215,6 \mathrm{aA}$ & $118,8 \mathrm{aB}$ & 1,8 & $908,2 \mathrm{aA}$ & $270,5 \mathrm{aB}$ & 3,3 \\
Sete & $351,4 \mathrm{aA}$ & $203,4 \mathrm{bB}$ & 1,7 & $216,5 \mathrm{aA}$ & $152,3 \mathrm{bB}$ & 1,4 & $846,5 \mathrm{aA}$ & $551,4 \mathrm{bB}$ & 1,6 \\
Nove & $344,5 \mathrm{aA}$ & $201,7 \mathrm{bB}$ & 1,7 & $217,3 \mathrm{aA}$ & $162,5 \mathrm{bB}$ & 1,3 & $837,2 \mathrm{aA}$ & $555,7 \mathrm{bB}$ & 1,5 \\
\hline
\end{tabular}

Para cada variável, médias seguidas por letras distintas minúsculas na coluna ou maiúsculas na linha diferem entre sí (P<0,05).

\section{DISCUSSÃO}

A coluna vertebral dorsolateral consiste em um ambiente desafiador para a formação óssea, diferente do que acontece com ossos longos. Material que apresenta resultados satisfatórios em defeitos ósseos pode não se comportar da mesma forma na união vertebral dorsolateral lombar (Martin et al., 1999). A utilização isolada da MOD na união vertebral não demonstrou resultados satisfatórios, e poucos estudos foram realizados em relação à utilização da $\mathrm{MO}$ na união vertebral (Damien e Parsons, 1991). A associação desses compostos pode ser uma opção exeqüível e de baixo custo, motivo pelo qual foi realizado este estudo.

As análises radiográficas demonstraram aumento gradativo da radiopacidade na região do enxerto no decorrer do período pós-operatório, nos animais do G1. O tecido de união apresentou, desde às cinco semanas, homogeneidade em toda sua extensão, que pode ser atribuída à ação da medula óssea distribuída ao longo da matriz desmineralizada. Também a MOD foi responsável pela deposição óssea de forma organizada e restrita ao ambiente, atuando como arcabouço osteocondutor. Tal condição também foi observada por Damien e Parsons (1991) e Guizard et al. (1992).

A diminuição do índice de união na sétima semana de sacrifício, de $87,5 \%$ para $75 \%$, coincide com a presença de abscesso unilateral encontrado em dois animais do G1, o que, provavelmente, determinou a não incorporação do enxerto.

A incongruência entre os dados radiográficos e o exame por palpação pode ser explicada pelos resultados histológicos. Houve casos em que animais foram classificados como não-união, cujas áreas radiolucentes presentes na radiografia histologicamente foram representadas por ilhas de cartilagem. Mas à palpação, a área operada estava firme e sem mobilidade, sendo considerada a ocorrência de união. Isto significa que nem sempre os achados radiográficos refletiram a condição clínica real do paciente.

A vascularização e as ilhas de tecido condróide no centro da região de enxertia (Fig. 2), à quinta semana após a cirurgia, coincidem com os achados de Wilson et al. (1985), que afirmaram que a incorporação do enxerto ósseo está diretamente relacionada à vascularização e presença de material osteogênico no local. Nas semanas seguintes de avaliação, a ossificação ocorreu de forma endocondral, predominantemente a partir das áreas descorticadas dos processos transversos, que atuaram fornecendo nutrientes. Segundo Ishikawa et al. (1994), a descorticação é procedimento essencial para ocorrência da integração do enxerto.

Nesta pesquisa, na nona semana, foi observada área de osso trabecular maduro comunicando-se com a região receptora dos processos transversos descorticados durante a cirurgia, que pode ser imputado a ação das células medulares associadas ao enxerto ósseo desmineralizado que, segundo Wittbjer et al. (1983) e Barros et al. (2001), influenciam a osteogênese nos estágios iniciais de cura, adiantando o processo.

Morone e Boden (1998) citaram que a quantidade de proteína morfogenética óssea (BMPs) liberada a partir da desmineralização não é suficiente para intensificar a formação óssea na coluna vertebral. Contudo, no presente estudo, a adição da MO pareceu incrementar a propriedade osteoindutora da MOD, tal como foi relatado por Frenkel et al. (1993), Maddox et al. (2000) e Barros et al. (2001). A medula óssea, além de fornecer células osteoprogenitoras, fornece 
fatores de crescimento que se somam à atividade osteoindutora, determinada pela BMP presente na MOD (Kalfas, 2001).

Houve diferença entre os grupos quanto ao índice de rigidez. O maior índice de rigidez indica que as vértebras que receberam o enxerto ósseo e medula suportaram mais força e deformaram menos que as vértebras-controle submetidas à mesma carga; para a coluna vertebral, submetida a forças deformantes constantes, quanto maior o índice de rigidez da massa óssea, maior a estabilidade do segmento e conseqüente sucesso da união vertebral e resolução da sintomatologia dolorosa.

Os segmentos tratados mostraram maior resistência biomecânica quando comparados aos segmentos não tratados. Isto demonstra que o tecido ósseo foi o responsável pela maior resistência dos segmentos tratados em comparação com os do grupo-controle.

Boden et al. (1995) realizaram testes biomecânicos com o mesmo protocolo, porém utilizaram o autoenxerto da crista ilíaca e obtiveram resultados semelhantes ao encontrado no presente experimento. Esses autores determinaram em coelhos, média do índice de força ao ponto de ruptura igual a $1,78 \pm 0,13,10$ semanas após a cirurgia. Neste estudo a média de todos os animais tratados com MOD e medula óssea apresentaram valores bem próximos, $1,78 \pm 0,23$. Presume-se que o comportamento do tecido formado pelo enxerto ósseo de MOD associado à medula óssea frente aos testes foi semelhante ao demonstrado pelo tecido formado pelo autoenxerto da crista ilíaca.

\section{CONCLUSÕES}

Em coelhos, a matriz óssea homóloga desmineralizada associada à medula óssea autógena fresca e depositada sobre os processos transversos descorticados das vértebras lombares cinco e seis determina a formação de tecido ósseo homogêneo em toda sua extensão, cuja vascularização origina-se, predominantemente, nos processos transversos descorticados. $\mathrm{Na}$ interface osso/enxerto a ossificação endocondral gradativamente substitui a matriz, propiciando ao segmento operado maior resistência mecânica em comparação aos segmentos adjacentes.

\section{REFERÊNCIAS BIBLIOGRÁFICAS}

BARROS, S.V.S.G.; DEL CARLO, R.J.; VILORIA, M.I.V. et al. Auto-enxerto percutâneo de medula óssea em coelhos. II. Reparação de falhas segmentares produzidas no rádio de coelhos. Ciên. Rural, v.23, p.1013-1018, 2001.

BODEN, S.D.; SCHIMANDLE, J.H.; HUTTON, W.C. An experimental lumbar intertransverse process spinal fusion model. Radiographic, histologic, and biomechanical healing characteristics. Spine, v.20, p.412423, 1995.

COOK, S.D.; DALTON, J.E.; PREWETT, A.B. et al. In vivo evaluation of demineralized bone matrix as a bone graft substitute for posterior spinal fusion. Spine, v.20, p.877-886, 1995

DAMIEN, C.J.; PARSONS, J.R. Bone graft and bone graft substitutes. A review of current technology and application. J. Appl. Biomat., v.2, p.187-208, 1991.

FEIGHAN, J.E.; STEVENSON, S.; EMERY, S.E. Biologic and biomecanic evaluation of posterior lumbar fusion in the rabbit - The effect of fixation rigidity. Spine, v.20, p.1561-1567, 1995.

FRENKEL, S.R.; MOSKOVICH, R.; SPIVAK, J. et al. Demineralized bone matrix. Spine, v.18, p.1634-1639, 1993.

GUIZZARD, S.; SILVESTRE, M.D.; SCANDROGLIO, $R$. et al. Implants of heterologous demineralized bone matrix for induction of posterior spinal fusion in rats. Spine, v.17, p.701-707, 1992.

ISHIKAWA, S.; SHIN, H.D.; BOWEN, J.R. et al. Is it necessary to decorticate segmentally instrumented spine to achieve fusion? Spine, v.19, p.1686-1690, 1994.

KALFAS, I.H. Principles of bone healing. Neurosurg. Focus, v.10, p.1-4, 2001.

MADDOX, E.; ZHAN, M.; MUNDY, G.R. et al. Optimizing human demineralized bone matrix for clinical application. Tissue Engineering, v.6, p.441-448, 2000.

MARTIN, G.J.; BODEN, S.D.; TITUS, L. et al. New formulation of demineralized bone matrix as a more effective graft alternative in experimental posterolateral lumbar spine arthrodesis. Spine, v.24, p.637-645, 1999.

MORONE, M.A.; BODEN, S.D. Experimental posterolateral lumbar spinal fusion with a demineralized bone matrix gel. Spine, v.23, p.159-167, 1998.

WILSON, J.W.; RHINELANDER, F.W.; STEWART, C.L. Vascularization of cancellous chip bone grafts. Am. J. Vet. Res., v.46, p.1691-1699, 1985.

WITTBJER, J.; PALMER, B.; ROHLIN, M. et al. Osteogenetic activity in composite grafts of demineralized compact bone and marrow. Clin.Orth. Rel. Res., n.173, p.229-238, 1983. 